Dicenda. Cuadernos de Filología Hispánica

ISSN: 0212-2952

http://dx.doi.org/10.5209/DICE.57706

\title{
Relaciones literarias en el siglo XV: García de Pedraza, Diego Hurtado de Mendoza y los juegos poéticos cortesanos ${ }^{1}$
}

\author{
Laura López Drusetta²
}

Resumen. Este trabajo se centra en el dezir ID2431 "Buen senyor Diego Furtado" (SA7-39) de García de Pedraza, una de las piezas más singulares del repertorio de este todavía poco conocido escritor cancioneril, responsable de catorce textos transmitidos en testimonio único a través del Cancionero de Palacio (c. 1441-1445). De contenido amoroso, la composición interesa en tanto vivo y original testimonio del juego poético en boga en los ambientes palaciegos cuatrocentistas, pero, sobre todo, en cuanto aporta informaciones sobre el autor y el dedicatario del dezir, el también poeta Diego Hurtado de Mendoza. Y es que, en numerosas ocasiones, el estudio detenido de los textos cancioneriles arroja reveladores datos acerca de la biografía del personaje, de sus conexiones literarias o del entorno en el que sus poemas se gestaron o difundieron. Este dezir es un ejemplo paradigmático de ello, pues tanto el epígrafe que lo presenta (Dezir. Garçía de Pedraza a Diego Furtado de Mendoza) como su contenido y distribución en la antología evidencian la relación literaria y vital que existió entre los dos autores, una circunstancia esencial para determinar la identidad de ambos.

Palabras clave: García de Pedraza; Diego Hurtado de Mendoza; Cancionero de Palacio; poesía cancioneril.

\section{[en] Poetic relationships in the fifteenth century: García de Pedraza, Diego Hurtado de Mendoza and courtly games}

\begin{abstract}
This article focuses on the dezir ID2431 "Buen senyor Diego Furtado" (SA7-39) by García de Pedraza, a little-known cancionero author with only fourteen surviving poems, all of which are unique to the Cancionero de Palacio (c. 1441-1445). This composition is not only an interesting and original witness to the courtly games of the fifteenth century, but also a valuable source of information about the writer and his addressee, the poet Diego Hurtado de Mendoza. Studying a text of this kind may throw light on its author's biography, his literary connections or the circles in which he moved. That is the case with this poem: its rubric (Dezir. Garçia de Pedraza a Diego Furtado de Mendoza), its subject matter and its position in the anthology reveal a clear association between the poets and important clues to their identities.
\end{abstract}

Keywords: García de Pedraza; Diego Hurtado de Mendoza; Cancionero de Palacio; cancionero poetry.

Cómo citar: López Drusetta, L. (2017). Relaciones literarias en el siglo XV: García de Pedraza, Diego Hurtado de Mendoza y los juegos poéticos cortesanos, Dicenda. Cuadernos de Filología Hispánica, $35,167-184$.

\footnotetext{
Este trabajo se inscribe en el marco del proyecto FFI2013-47746-P, financiado por el Ministerio de Economía y Competitividad; ha podido llevarse a cabo gracias al disfrute de una beca FPU del Ministerio de Educación, Cultura y Deporte. Para la cita de textos y fuentes cancioneriles, se siguen las convenciones de Dutton (1990-1991).

2 Universidade da Coruña

laura.drusetta@udc.es
} 
En un conocido artículo, Deyermond hacía hincapié en el alcance que adquirieron las relaciones literarias en la poesía del siglo XV, una época en la que, en sus propias palabras, "los autores llegan a ser el tema de la literatura, sea en elogios y elegías, sea como víctimas de sátiras, sea al convertirse en personajes ficcionalizados" (Deyermond, 2005a: 73). Una simple ojeada a los índices de El cancionero del siglo XV (c. 1360-1520) puede dar una idea cabal de la magnitud del fenómeno: solo entre los destinatarios de poemas, aparecen registrados cerca de 600 nombres, un número elevado si se tiene en cuenta que este investigador individualiza aproximadamente a 700 autores cancioneriles (Dutton, 1990-1991, VII: 474-482) 3 $^{3}$ Ello encuentra su explicación en la propia naturaleza de la poesía cuatrocentista, fruto de una cultura aristocrática en la que el ejercicio literario se concibe como juego social cortesano: en las postrimerías de la Edad Media y aun en épocas posteriores, se celebran justas, torneos, pasos de armas y fiestas palaciegas en las que los caballeros rivalizan en destreza y que se constituyen en actividad social relevante; también el trovar se convirtió en elemento característico de este tipo de reuniones, pues el caballero exhibía así su habilidad y pericia en la gaya ciencia ${ }^{4}$.

Si hay un florilegio en el que el carácter lúdico-cortesano de este tipo de poesía se hace evidente, ese es el Cancionero de Palacio (SA7), colectánea manuscrita en la que son frecuentes los diálogos, los poemas escritos en colaboración, las citas intertextuales, así como otro tipo de manifestaciones que permiten establecer nexos entre los textos y autores compilados en esta colección, que acoge lo que circulaba en los entornos áulicos de Castilla y Aragón en la primera mitad del XV (Tato, 2012: $302)^{5}$. Es precisamente en esta fuente donde se copió la pieza objeto de este trabajo, ID2431 "Buen senyor Diego Furtado" (SA7-39), presentada en la rúbrica como Dezir. Garçía de Pedraza a Diego Furtado de Mendoza. El poema, al igual que las trece composiciones restantes del autor, fue transmitido únicamente a través de este cancionero - una circunstancia nada excepcional, pues el florilegio sobresale por su alto número de unica (Tato, 2005: 68-69)-, y es uno de los más interesantes de su producción.

Centrando la atención en el texto, uno de los aspectos sobre los que conviene incidir tiene que ver con su destinatario; y es que no solo la rúbrica que lo acompaña indica que el poema fue dirigido a Diego Hurtado de Mendoza, sino que esta figura es interpelada en el primer verso ("Buen senyor Diego Furtado, / de la paç conservador", vv. 1-2), pues García de Pedraza le solicita su intercesión para el logro del favor amoroso que ansía conseguir ${ }^{6}$. La lectura atenta del dezir revela, además, que el citado Diego Hurtado hubo de estar presente en el entorno en el que sonaron los versos, como se percibe a través de diversas marcas gramaticales que lo caracterizan

\footnotetext{
Téngase en cuenta, no obstante, que no todos los destinatarios se corresponden con escritores cancioneriles.

Sobre el componente lúdico de la poesía cortesana, puede consultarse Rodado Ruiz (2000: 34-46), donde se aporta otra bibliografía.

5 Véanse también Dutton (1979: 447-456) y Beltran (2001: 68-71). A pesar de su escasa fortuna crítica inicial, eclipsada por la temprana publicación del Cancionero de Baena (PN1) en 1851, en los últimos años, los estudios sobre el Cancionero de Palacio (SA7) han experimentado un considerable auge, siendo hitos fundamentales para el conocimiento de la antología los trabajos de Tato (2000, 2003, 2005, 2006, 2010a, 2012), amén de las dos ediciones disponibles, a cargo de Vendrell (1945) y Álvarez Pellitero (1993).

6 Al contrario de lo que sucede en el Cancionero de Baena, cuyas rúbricas suelen contener informaciones sobre las circunstancias de composición de las piezas, en SA7 lo habitual es que estos epígrafes consignen solo el nombre del autor y/o la categoría poética del poema que presentan. Sobre las rúbricas cancioneriles, véase Garribba (2008), donde se recogen varios trabajos consagrados a esta temática.
} 
como el interlocutor del yo que habla (vocativos, formas verbales de segunda persona, pronombres personales que igualmente llevan a la segunda persona, así como algún posesivo): "pido a vuestra senyoría" (v. 5), "Aún más, por que sepades, / buen senyor" (vv. 9-10), "vos puedo mostrar firmado" (v. 13), "e vos ruega sin çesar" (v. 19), "sea yo favorezido, / senyor, de vuestra nobleza" (vv. 21-22), "me fagáys canonizado" (v. 24), "pues que soys tan acavado, / de virtudes enserido, / fazetme ser influydo" (vv. 25-27)

Por si estos argumentos no fuesen suficientes, la ubicación del poema en el cancionero apunta en la misma dirección ya que, como puede observarse en el cuadro, se copia tras varios textos del también poeta de SA7 Diego Hurtado de Mendoza, composiciones que presumiblemente Pedraza conoció pues, según se puede apreciar, mencionó dos de ellas en otro dezir citador que figura antes en el manuscrito:

\begin{tabular}{|c|c|c|c|c|c|c|}
\hline & $\mathrm{N}^{\mathrm{o}}$ & Folio & ID & Autor & Rúbrica & Íncipit \\
\hline \multirow{6}{*}{ 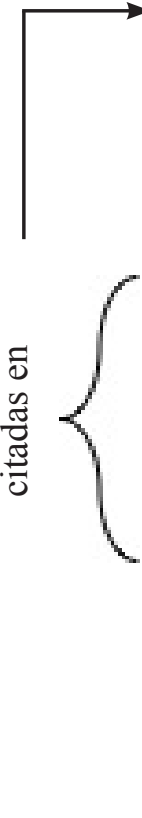 } & SA7-22 & $9 r-10 v$ & 2413 & $\begin{array}{l}\text { García de Pe- } \\
\text { draza }\end{array}$ & $\begin{array}{l}\text { Dezir Garçia de } \\
\text { Pedraça }\end{array}$ & $\begin{array}{l}\text { Sepan quan- } \\
\text { tos esta carta }\end{array}$ \\
\hline & \multicolumn{6}{|c|}{$\begin{array}{l}\text { SA7-23 a SA7-35 (folios 10r a 14r), secuencia a cargo de varios autores (García } \\
\text { de Pedraza, Íñigo López de Mendoza, Juan de Dueñas, Francisco Bocanegra, } \\
\text { etc.) }\end{array}$} \\
\hline & SA7-36 & $14 \mathrm{r}-\mathrm{v}$ & 2414 & $\begin{array}{l}\text { Diego Hurtado } \\
\text { de Mendoza }\end{array}$ & $\begin{array}{l}\text { Cançion Die- } \\
\text { go Furtado de } \\
\text { Mendoça }\end{array}$ & $\begin{array}{l}\text { Fuerça he de } \\
\text { contemplar }\end{array}$ \\
\hline & SA7-37 & $14 \mathrm{v}$ & $\begin{array}{l}2430 \\
\text { D } \\
2414\end{array}$ & $\begin{array}{l}\text { Diego Hurtado } \\
\text { de Mendoza }\end{array}$ & Mudança & $\begin{array}{l}\text { Si amor sse } \\
\text { que se parte }\end{array}$ \\
\hline & SA7-38 & $14 \mathrm{v}$ & 2417 & $\begin{array}{l}\text { Diego Hurtado } \\
\text { de Mendoza }\end{array}$ & $\begin{array}{l}\text { Cançion el mes- } \\
\text { mo }\end{array}$ & $\begin{array}{l}\text { Amor quando } \\
\text { me quitaste }\end{array}$ \\
\hline & SA7-39 & $15 r$ & 2431 & $\begin{array}{l}\text { García de Pe- } \\
\text { draza }\end{array}$ & $\begin{array}{l}\text { Dezir Garçia de } \\
\text { Pedraza a Die- } \\
\text { go Furtado de } \\
\text { Mendoza }\end{array}$ & $\begin{array}{l}\text { Buen senyor } \\
\text { Diego Furta- } \\
\text { do }\end{array}$ \\
\hline
\end{tabular}

Pero no solo en esta ocasión aparecen textos de García de Pedraza colindando con los de Diego Hurtado: su canción ID2410 "Por ser de ti namorado" (SA7-18) aparece tras el cosaute ID2408 "Aquel arbol que buelbe la foxa" (SA7-16) y la serrana ID2409 "Vn dia desta semana" (SA7-17) de Diego Hurtado de Mendoza, lo que, sin duda, se explica por la relación literaria que unió a estos dos autores, cuyos poemas figuran en vecindad debido a que hubieron de gestarse o circular en un mismo ambiente ${ }^{8}$.

A la vista de estas significativas disposiciones de sus piezas, pocas dudas caben sobre la veracidad de la información proporcionada por el epígrafe de Palacio: el

\footnotetext{
Tomo las citas del poema de la edición del Cancionero de Palacio a cargo de Álvarez Pellitero (1993: 33-34), de la que extraigo también el texto íntegro que figura como apéndice a este estudio; las cursivas son mías.

8 Sobre la utilidad de la revisión del orden y posición de los poemas en los cancioneros ya llamó la atención Beltran (1998: 21) y, particularmente para el caso del Cancionero de Palacio, Tato, quien considera este uno de los aspectos menos atendidos (2012: 307).
} 
escritor Diego Hurtado, a quien, según se desprende del texto, Pedraza trató personalmente, fue, en efecto, el destinatario de este dezir ${ }^{9}$. La circunstancia, que a priori podría parecer poco significativa, cobra relevancia al revisar las biografías de estos dos personajes, pues mientras que Diego Hurtado de Mendoza ha sido identificado, desde la época del inicio de los estudios cancioneriles, con el almirante de nombre homónimo padre del marqués de Santillana (nac. c. 1366 - †1404), a García de Pedraza se le ha atribuido más de una personalidad, sin que exista todavía un acuerdo ${ }^{10}$. La dificultad que entraña individualizar al pedrazano viene dada precisamente por sus relaciones literarias: no solo dirige este dezir al poeta y supuesto almirante de Castilla Diego Hurtado de Mendoza - cuya cronología llevaría al último tercio del siglo XIV-, sino que también compone una serrana en colaboración con Rodrigo Manrique (1406-1476) y el marqués de Santillana (1398-1458) -el poema que comienza con ID2424 "De Loçoya a Navafria" (SA7-28) ${ }^{11}$ - y realiza una imitación paródica del Infierno compuesto por este último (ID2406 "Partiendo de madrugada" [SA7-13]), piezas ambas que hubieron de ser creadas entre el segundo y el cuarto decenio del siglo $\mathrm{XV}^{12}$.

Estas conexiones poéticas implicarían que el escritor Pedraza habría desarrollado su actividad literaria en el entorno de la familia Mendoza y en los años que transcurren, aproximadamente, entre 1380 y 1430 (Dutton, 1990-1991, VII: 376 y 414), una coyuntura, si no imposible, bastante improbable habida cuenta de la amplitud del

9 No sucede lo mismo en el caso de ID2432 "Fernando senyor sabet" (SA7-40), también de García de Pedraza, cuya rúbrica lo hace dedicado a Fernando de Sandoval pero que, según demostraron Campos Souto y Chas Aguión en sus respectivos estudios, muy probablemente esté dirigida en realidad a Fernando de Guevara, primo de Santillana y autor del texto siguiente, ID2433 "Juras a nuestro señor" (SA7-41), un juramento de amor que viene anunciado ya en la composición del pedrazano -véase Campos Souto (2008: 25) y Chas Aguión (2012a: 203-204). Para los problemas de autoría y atribución en los cancioneros, pueden consultarse Moreno (1998), Beltran (2004) o Tato (2010a).

10 Sobre las propuestas de identificación de García de Pedraza véase López Drusetta (2015: 851-853). Hasta donde he podido saber, fue en la introducción de la primera edición del Cancionero de Baena bajo el patrocinio del marqués de Pidal donde, por vez primera, se identificó a Diego Hurtado de Mendoza con el almirante de Castilla así llamado y padre del marqués de Santillana -sin ofrecer ninguna justificación-(1851: XLI), una asunción que fue perpetuada por Ríos (1861-1865, V: 288-294) y, desde él, por toda la crítica posterior; véase López Drusetta (2014).

11 Aun cuando Dutton otorga un número ID distinto a cada una de las intervenciones en esta serrana, se trata de un mismo texto escrito en colaboración; ello se hace evidente en el plano formal, pues es una canción de tres vueltas a la que cada autor aporta una estrofa: Rodrigo Manrique se encarga de la cabeza y primera vuelta (ID2424 "De Loçoya a Navafria" [SA7-28]), Santillana de la segunda (ID2425 R 2424 "Serrana tal casamiento" [SA729]) y Pedraza de la tercera (ID2426 R 2425 "Serrana si vos queredes" [SA7-30]). En adelante citaré esta pieza abreviadamente con el íncipit de la primera de sus intervenciones.

12 La serrana en colaboración entre Rodrigo Manrique, Íñigo López de Mendoza y García de Pedraza es otro de los interesantes poemas que se cuentan en su reportorio poético; en cuanto a su fecha de composición, y a pesar de que todavía no existe acuerdo, la cronología de Santillana (1398-1458) y, sobre todo, la de Rodrigo Manrique (1406-1476) aconsejan ubicarlo temporalmente no antes de la segunda década del siglo XV. En situación análoga se encuentra la imitación paródica del Infierno santillanesco llevada a cabo por el de Pedraza (el dezir ID2406 "Partiendo de madrugada" [SA7-13]), pues su fecha de composición viene determinada por la del modelo de Íñigo López, escrito después de 1427-1428, años en los que debieron de llegar a sus manos las traducciones de la Eneida y la Divina Comedia realizadas por su tío Enrique de Villena, dos obras cuya lectura reciente se percibe con claridad en el Infierno (Lapesa, 1957: 96). En lo que atañe a la fecha límite de creación de las piezas, esta ha de coincidir con la de compilación de SA7, establecida con sólidos argumentos antes de 1445 (Ríos, 1852: CLXIV-CLXV; Dutton, 1979: 447-456) y muy probablemente también anterior a 1441 (Beltran, 2001: 68-71). Un análisis detenido de la serrana a tres voces puede encontrarse en Campos Souto (2008); sobre la imitación paródica del Infierno de Santillana véase López Drusetta (2013). 
período ${ }^{13}$. La circunstancia ya llamó la atención de Vendrell, quien, quizás detectando este problema cronológico, descartó en su edición de SA7 que el dezir ID2431 "Buen senyor Diego Furtado" (SA7-39) hubiese sido dirigido al almirante Diego Hurtado de Mendoza (personaje que, en su opinión, se correspondía con el poeta de SA7 de igual nombre). Según esta editora, el texto que aquí interesa habría sido dedicado, en realidad, a otro individuo de nombre Diego Hurtado de Mendoza distinto del poeta y supuesto almirante -según ella, el destinatario era el hijo de Juan Furtado así llamado- (Vendrell, 1945: 60); sin embargo, su hipótesis resulta ciertamente improbable pues, como he indicado, Pedraza citó versos del escritor Diego Hurtado en otro de sus dezires.

Pero es la investigación sobre la figura histórica de este autor la que definitivamente echa por tierra estas ideas, al no haber localizado ningún personaje de nombre García cuyo apellido o lugar de origen o señorío haya sido Pedraza durante el período en que, pretendidamente, mantuvo vinculaciones poéticas tanto con el almirante Diego Hurtado de Mendoza (nac. $c$. 1366 - †1404) como con su hijo el marqués de Santillana (1398-1458) ${ }^{14}$. Con todo, existen dos Garcías que ostentaron el señorío de Pedraza de la Sierra (actual provincia de Segovia) durante los siglos XIV y XV respectivamente: el mariscal García González de Herrera, primer señor de Pedraza (nac. c. 1344 - $† 1404$ ) y su nieto García de Herrera y Enríquez, tercer señor de Pedraza (nac. c. $1415-\dagger 1483)^{15}$. Es claro que alguno de ellos ha de corresponderse con el creador de SA7, no solo por la coincidencia antroponímica y toponímica, sino también porque la localidad de Pedraza de la Sierra se encuentra cercana a la de Buitrago del Lozoya, señorío de Íñigo López de Mendoza, un escritor muy vinculado poéticamente con el pedrazano, según ya he manifestado. Así las cosas, la cronología de estos dos señores de Pedraza no armoniza con las pretendidas relaciones literarias del escritor cancioneril oriundo de esta localidad: mientras que el primer señor de Pedraza (nac. c. 1344 - †1404) murió antes de que Rodrigo Manrique naciese (1406-1476), su nieto, el tercer señor de Pedraza (nac. c. $1415-\uparrow 1483$ ), nació aproximadamente diez años después de la muerte del

3 Por otro lado, la distribución de las piezas del pedrazano en el Cancionero de Palacio trasluce, asimismo, su relación con la familia Mendoza, pues no solo aparecen poemas suyos en vecindad con los de Diego Hurtado de Mendoza, sino que son también bastantes los que se anteponen o posponen a composiciones de Íñigo López de Mendoza, lo que refuerza la idea de Campos Souto: "no parece imposible suponer que sus textos (se refiere a los de Pedraza) hayan entrado en SA7 de la mano de los Mendoza ya que, precisamente, de su lectura deducimos el vínculo o la relación que debió de existir entre García de Pedraza y los miembros de este linaje" (Campos Souto, 2008: 23). Para más información sobre la distribución de los poemas de García de Pedraza en SA7 puede consultarse López Drusetta (2017a).

14 Ya desde mediados del siglo XII, se empieza a utilizar el lugar de origen o señorío como clave para distinguir individuos entre sí, especialmente en el caso de linajes nobiliarios; es importante subrayar que no se trata de un apellido, pues rara vez los miembros de la familia firman o se autodenominan con tal término distintivo, sino de una denominación utilizada por la sociedad por motivos prácticos (Salazar y Acha, 2006: 278).

15 Prescindo en este estudio de la identificación propuesta por algunos críticos para García de Pedraza, según la cual este habría de ser el mariscal Pedro García de Herrera -véanse Pérez Priego (1999: 43-44 y 127) y Campos Souto (2011: 133-146)-; y es que, al contrario de lo que se ha creído, el mariscal Pedro García de Herrera nunca fue señor de Pedraza ni tuvo vinculación con esa villa, como se puede corroborar en su testamento (conservado en el Archivo General de Simancas con la signatura CME, 51, 47). La coincidencia parcial de su nombre y apellidos con los de los personajes que sí fueron señores de Pedraza - probablemente emparentados con este mariscal por el apellido Herrera- motivó la confusión. Por otro lado, el segundo señor de Pedraza, cronológicamente situado entre el abuelo y nieto, se llama Pedro Núñez de Herrera (y no García), por lo que tampoco lo he tenido en cuenta. Sobre estas cuestiones véase López Drusetta (2015). 
almirante Diego Hurtado de Mendoza (nac. c. 1366 - $\uparrow 1404$ ), lo que excluiría a ambos candidatos.

La circunstancia resulta ciertamente llamativa y pone sobre aviso de que quizá las premisas de las que se ha partido no son las adecuadas; y es que el único lazo que ata literariamente al escritor García de Pedraza al siglo XIV es el que lo liga al supuesto almirante y poeta Diego Hurtado de Mendoza (nac. c. $1366-\uparrow 1404$ ), toda vez que tanto su serrana con Rodrigo Manrique y Santillana como su imitación paródica del Infierno llevan indiscutiblemente a hablar de un autor de la primera del siglo XV, perfectamente identificable con el tercer señor de Pedraza García de Herrera y Enríquez (nac. c. 1415 - 1483 ). El estudio demorado de su poesía apunta, asimismo, hacia un escritor que gozó de cierta trascendencia en los círculos poéticos del reinado de Juan II de Castilla: las catorce composiciones suyas que se copian en el Cancionero de Palacio -única fuente de sus creaciones- hacen de él, por número de obras, el quinto poeta mejor representado en este manuscrito; la cifra lo sitúa casi a la par del marqués de Santillana y de Álvaro de Luna, personajes bien conocidos y de gran importancia en el entorno cortesano, que figuran en el cancionero con quince textos cada uno.

De particular interés para el conocimiento del perfil poético del pedrazano resulta, además, la ya aludida revisión del orden y posición de sus piezas en el manuscrito salmantino, pues la mayor parte de ellas pueden vincularse con los textos que las rodean, ya sea porque aparecen cercanas o en vecindad directa con poemas de autores con los que mantiene relaciones literarias (he mencionado los casos de Diego Hurtado de Mendoza y el marqués de Santillana, pero lo mismo ocurre con otros escritores como Francisco Bocanegra o Fernando de Guevara), ya porque tocan la misma temática, se adscriben al mismo género, etc. Por citar algunos ejemplos, su imitación paródica del Infierno santillanesco se encuentra entre dos textos que también recuerdan a ese dezir de don Íñigo y debidos, respectivamente, a las plumas de Pedro de Quiñones (ID2405 "Por la fin del que bien ama" [SA7-12]) y Juan Pimentel (ID2254 "Quando tu a mi oyas [SA7-14]), lo que parece sugerir un contexto de creación o circulación común para los tres (Tato, 2005: 78); algo similar ocurre con su aguinaldo ID2423 "Pues demando aguinaldo" (SA7-27), que sigue a otra pieza de esa misma categoría poética escrita por Juan de Dueñas (ID0488 "Aunque veo ques mi danyo" [SA7-26]) (Campos Souto, 2008: 30); también su serrana a tres voces con Rodrigo Manrique y Santillana (ID2424 "De Loçoya a Navafria" [SA7-28], etc.) se copió entre otras piezas de esa modalidad literaria (Garcia, 2005: 28-31).

Las conexiones poéticas de García de Pedraza no se limitan, pues, a Santillana, sino que alcanzan a otros autores de la primera mitad del siglo XV como Rodrigo Manrique, Fernando de Guevara, Francisco Bocanegra, Pedro de Quiñones, Juan Pimentel, Juan de Dueñas, etc., escritores todos ellos (incluido el pedrazano) que es posible poner en conexión con uno de los círculos poéticos que debieron de constituirse en torno a la figura de Íñigo López de Mendoza (López Drusetta, 2017a), figura central de las relaciones literarias durante la primera mitad del siglo XV (Deyermond, 2005a: 83).

Al hilo de lo anterior, estas reflexiones conducen a la inevitable cuestión de si fue realmente el almirante Diego Hurtado de Mendoza (nac. c. 1366 - $\uparrow 1404$ ) el destinatario del dezir objeto de estudio y, por tanto, el poeta cuyos versos se copiaron en SA7 bajo esa atribución o si, como a menudo sucede, se trata de uno de los nume- 
rosos casos de homonimia que se producen en este período ${ }^{16}$. Según he expuesto en otro lugar, parece que hemos de aceptar que la identificación del escritor cancioneril Diego Hurtado de Mendoza con el almirante de igual nombre responde tan solo a una asociación propuesta en el siglo XIX y perpetuada hasta la actualidad; toda vez que existen pruebas irrefutables de que el autor así llamado vivió y ejercitó su pluma durante la primera mitad del cuatrocientos. La de mayor peso la proporciona, precisamente, el texto que ahora interesa, que García de Herrera y Enríquez, tercer señor de Pedraza (pues ha de ser este individuo el autor de los catorce poemas que se copiaron en SA7 bajo la atribución García de Pedraza; véase López Drusetta, 2015), dedicó durante la primera mitad del siglo XV a otro creador de nombre Diego Hurtado de Mendoza, quien, necesariamente, se encontraba presente durante la interpelación ${ }^{17}$.

Este Diego Hurtado, dedicatario del dezir y autor de varios textos conservados en el Cancionero de Palacio, hubo de ser, según he concluido tras un demorado estudio literario y biográfico, Diego Hurtado de Mendoza y Figueroa (nac. c. 1415-1417 - †1479), el hijo primogénito del marqués de Santillana y después primer duque del Infantado. Y es que tanto su perfil vital (formación intelectual de la mano de su padre Íñigo López, acceso a su rica biblioteca, temprana inclusión en los entornos cortesanos), como la relación literaria de su progenitor, el marqués de Santillana, con García de Pedraza inclinan la balanza a favor de esta identificación; sin olvidar tampoco que se trata de un hombre de una edad muy próxima -si no igual-a la del pedrazano, a quien habría conocido a través de su padre ${ }^{18}$.

Descubiertas las identidades de autor y dedicatario, sin duda uno de los aspectos más interesantes del poema, conviene ahora llamar la atención sobre otras de sus características: formalmente, se trata del dezir más breve del repertorio poético de Pedraza (escribió cinco más), pues se compone de tres estrofas octosílabas seguidas de una finida ${ }^{19}$. Si bien en las dos primeras se sigue el esquema de coplas castellanas constituidas por dos semiestrofas con cuatro rimas abrazadas abbacddc (uno de los más frecuentes en el Cancionero de Palacio; Tato, 2016: 716-717), no ocurre lo mismo en la tercera, que rompe esta regularidad con una combinación abbacdde; la circunstancia tal vez responda a un problema en la transmisión textual ${ }^{20}$.

En cuanto al asunto del poema, se trata de una composición en la que García de Pedraza realiza una solicitud distendida e ingeniosa al de Mendoza con la finalidad

16 Otros ejemplos del fenómeno en poesía cancioneril pueden encontrarse en Giuliani (1991), Tato (1998) o Bel$\operatorname{tran}(2001)$.

17 Esta y otras razones para sostener el argumento en López Drusetta (2014).

18 Diego Hurtado de Mendoza es otro de los interesantes poetas conocidos gracias a Palacio, cancionero en el que se copiaron sus siete únicas piezas conservadas: ID2395 "Pues no quiero andar en corte" (SA7-1), ID2400 "Ya con tanta fermosura" (SA7-6), ID2408 "Aquel arbol que buelbe la foxa" (SA7-16), ID2409 "Vn dia desta semana" (SA7-17), ID2414 "Fuerça he de contemplar" (SA7-36), ID2430 D 2414 "Si amor sse que se parte" (SA7-37) e ID2417 "Amor quando me quitaste" (SA7-38). Las cuestiones relativas a la biografía de Diego Hurtado son abordadas con detalle en López Drusetta (2017b).

19 Sus otros dezires cuentan con cuatro (ID2432 "Fernando senyor sabet" [SA7-40]), cinco (ID2411 "Traslado de alegría" [SA7-20]), ocho (ID2413 "Sepan quantos esta carta" [SA7-22]), nueve (ID2619 "O castillo tan famosso" [SA7-249]) y diez coplas (ID2406 "Partiendo de madrugada" [SA7-13]).

20 La irregularidad puede resolverse, como proponen Dutton y Roncero en su antología, sustituyendo el "favorezido" del manuscrito por un "favorizado", que no altera el esquema de rimas: "sea yo favorizado, / senyor, de vuestra nobleza, / e, que vista mi firmeza, / me fagáys canonizado" (vv. 21-24; véase Dutton y Roncero, 2004: 141-142). Para la métrica del texto, véase Gómez Bravo (1998: nn. 305-780, 1284-349..351. 
de lograr su intercesión para conseguir el favor amoroso que pretende. La temática, inserta en la tradición cortés de la primera mitad del siglo XV, se encuentra muy en la línea de la de otras piezas suyas consagradas a la expresión de una vivencia sentimental; y es que, tal y como sucede con su imitación del Infierno de Íñigo López de Mendoza (ID2406 "Partiendo de madrugada" [SA7-13]), con su serrana en colaboración con este y Rodrigo Manrique (ID2424 "De Loçoya a Navafria” [SA7-28], etc.) o con el juramento que presumiblemente pronuncia ante Fernando de Guevara (ID2432 "Fernando senyor sabet" [SA7-40] e ID2433 "Juras a nuestro senyor" [SA7-41]), en ID2431 "Buen senyor Diego Furtado" (SA7-39), Pedraza hace alarde de su habilidad para el juego socio-literario con relevantes figuras del momento, destreza que combina en todas estas composiciones con una natural propensión a la comicidad e ironía en el tratamiento del asunto amatorio, lo que hubo de hacer de él un habitual en las veladas poéticas cortesanas ${ }^{21}$.

En el dezir que ahora interesa, García de Pedraza se presenta ante Diego Hurtado como un firme seguidor de "aquel bendito / dios d'Amor que da cuydado" (vv. 1516), a quien, voluntariamente, sigue y venera ("Al qual, por mi petición, / le plugo de me guiar", vv. 17-18), pese a que ello solo le reporta calamidades ("yo, que tengo por amor / asaç penas et cuydado", vv. 3-4). Es esta injusta situación la que lo lleva a requerir la ayuda del Mendoza, al que el autor atribuye en la composición la potestad de interferir por él en sus asuntos amatorios, otorgándole un papel similar al de la máxima autoridad eclesiástica: no solo pide a don Diego el envío de un breve (documento pontificio de menor solemnidad que una bula $)^{22}$ con el que pretende obtener satisfacción carnal de sus deseos ("pido a vuestra senyoría / que quiera breve mandar: / que me dexen ya passar / por el puerto d'alegría", vv. 5-8), sino que, además, dada su fiel entrega al dios de Amor, le solicitará ser declarado santo, santidad a la que posiblemente haya de atribuírsele un sentido erótico ("e, que vista mi firmeza, / me fagáys canonizado", vv. 23-24).

Aunque quizás no sea imposible llegar a otras interpretaciones de los versos, dada la reducida extensión del poema y la falta de contexto, todo ello podría ponerse en relación con la religio amoris, formulación tópica según la cual el enamorado es un fiel acólito del Amor o de su dama, como el cristiano es siervo de Dios, y de ahí el trasvase del léxico derivado del campo semántico religioso aplicado al sentimiento amoroso (Casas Rigall, 1995: 85; Rodado Ruiz, 2000: 69) 23. En este caso,

21 Un panorama de su poética, con especial atención a los textos mencionados, en López Drusetta (en prensa).

22 El Diccionario de Autoridades define el término como "el Buléto Apostólico concedido por el Sumo Pontifice, ò por su legado à latere. Llamóse breve, porque se escribe y despacha sin las formalidades jurídicas" (s. v. breve).

23 A partir de la equiparación básica del Amor o la dama con el Dios cristiano, la religio amoris se despliega en un amplio abanico de posibilidades: salmos, misas, mandamientos o gozos de amor son solo algunas de sus múltiples manifestaciones; en este mismo sentido, mención especial merece la acomodación de pasajes bíblicos y de la liturgia cristiana como parte integrante de composiciones de carácter amoroso, un procedimiento que gozó de cierta vitalidad entre los autores cuatrocentistas. Sobre la religio amoris, véanse Lida de Malkiel (1977), Gerli (1981), Tillier (1985), Crosas (2000), Casas Rigall (1995: 85-87), Rodado Ruiz (2000: 68-70) o Gernert (2009), entre otros; para las citas bíblicas en contextos profanos, véanse Crosas (1999), Casas Rigall (1995: 176-186) o la reciente publicación de Saguar García (2015). Por otro lado, el Cancionero de Palacio atesora buenas muestras de esta formulación tópica, pues en él se copiaron piezas como el Miserere de Francisco de Villalpando (ID2484 G 7820 "Miserere mey deus" [SA7-91]), los Siete gozos de amor de Juan Rodríguez del Padrón (ID0192 “Ante las puertas del templo" [SA7-360]) o el Infierno de los enamorados de Íñigo López de Mendoza (ID0028 "La fortuna que non çessa" [SA7-250]), así como la ya mencionada imitación paródica del mismo a cargo de García de Pedraza (ID2406 "Partiendo de madrugada" [SA7-13]). 
Diego Hurtado de Mendoza se convierte en un personaje ficcionalizado que parece asimilarse con el Sumo Pontífice de la religión de amor o una figura análoga, aspecto perceptible tanto en el trato reverencial que el de Pedraza le brinda -se dirige a él como "buen senyor" (vv. 1 y 10) y "vuestra senyoría" (v. 5)- y las cualidades que le atribuye -"de la paç conservador" (v. 2), "vuestra nobleza" (v. 22), "soys tan acavado, / de virtudes enserido" (vv. 25-26)-, como, y especialmente, en las facultades que le asigna: don Diego es quien manda los breves, documentos cuya redacción corresponde al Papa -"pido a vuestra senyoría / que quiera breve mandar" (vv. 5-6)y el que tiene la potestad, asimismo, en lo referente a la canonización de individuos -"me fagáys canonizado" (v. 24)-, aspectos ambos, como es sabido, competencia del Sumo Pontífice romano ${ }^{24}$.

El tratamiento que se otorga al de Mendoza en la composición induce a pensar que el poema debe ser entendido como un juego que Pedraza le plantea a su dedicatario, quien quizá podría haber desempeñado un papel activo en el contexto en que se recitó el dezir (es posible que hubiese aparecido ataviado con unas ropas que emulasen la vestimenta del pontífice; tal vez incluso se trataba de una puesta en escena más efectista con participación de otros individuos, por cuanto se habla también del dios de Amor, etc.), una circunstancia hoy difícilmente demostrable pero que casaría bien con la dimensión dramática implícita de esta pieza. Y es que gracias al testimonio de las crónicas se pueden conocer algunos detalles sobre el carácter de espectáculo de ciertos pasatiempos cortesanos, que incluían lujosos atavíos y la creación de arquitecturas efímeras. Valga como ejemplo la fiesta que organizó Juan II para honrar las bodas de su prima doña Leonor, en uno de cuyos torneos el rey salió como Dios padre y otros doce caballeros lo acompañaron vestidos de santos, ataviados con diademas en las que figuraba el nombre del sujeto al que representaban y portando las señales de su martirio ${ }^{25}$; también fastuosas fueron las justas de 1434 de Valladolid, en las que la ceremonia de entrega de los premios se realizó como en la corte del dios de Amor, que la presidía (a Juan II le tocó como primer premio un caballo, a don Álvaro un yelmo adornado con las plumas de las alas de este dios, a Pedro de Quiñones una celada, etc. $)^{26}$. Sea como fuere, lo cierto es que don Diego no solo sirve de pretexto para iniciar la declamación ("Buen senyor Diego Furtado", v. 1), sino que es el co-protagonista absoluto del poema, lo que reafirma la hipótesis de que hubo de estar presente durante la interpelación.

24 De especial interés resulta el que se refiera a él como "de la paç conservador" (v. 2) y "de virtudes enserido" (v. 26), dos designaciones que parecen apuntar igualmente hacia el ámbito eclesiástico. En lo que respecta a la primera, el paciario o conservador de la paz fue un cargo sobre el que existen varias definiciones: Domínguez apunta que "en 1224 se dio este título á los enviados á Montpeller por la córte de Roma, para asegurar la paz como asimismo á Tolosa de Francia en 1229" y que fue otorgado también por el Papa Clemente IV a Carlos I de Sicilia (18461847: s. v. paciario; sobre el nombramiento de Carlos de Anjou para este puesto se hace eco Zurita, véase Canellas López, 1977-1990, III: 1xxviii); por su parte, Alemany y Bolufer lo define como el "delegado pontificio cerca de los príncipes encargados por el Papa de mantener la paz" o "príncipe encargado por el Papa de mantener la paz en ciertos estados" (1917: s. v. paciario), lo que nuevamente vincula el cargo al papado. En lo que atañe a "de virtudes enserido" (v. 26), es este un sintagma que se localiza también en ID3662 "Ante santo que nascido" de Juan Martínez de Burgos (v. 8), una composición que el autor dedica a San Juan Bautista; el uso de tal construcción en otra pieza de carácter religioso sugiere que esta caracterización podría ser propia de este ámbito.

25 Para la narración del episodio, véase Carriazo (2006: 24-25); también Rico (1990: 179-180).

26 Un relato de estas justas en Carriazo (2006: 154-156 y 1946: 150-154). Sobre la espectacularidad y ostentación de las fiestas cortesanas durante el período son útiles los trabajos de Palomo Fernández y Senra Gabriel y Galán (1994) y Oreja Andrés (2013). 
Más difícil, si no imposible, resulta saber si respondió literariamente a la solicitud del pedrazano, quien le demandaba la redacción de un breve de contenido amoroso; merced a los testimonios existentes nada puede decirse, al no haberse conservado ninguna pieza del Mendoza que posea estas características. Con todo, no por ello debe excluirse la posibilidad de que Diego Hurtado hubiese contestado con un poema, pues es demostrable el interés de Pedraza por este tipo de juegos poéticos cortesanos: en el dezir que sigue al que ahora interesa en el cancionero (la composición ID2432 "Fernando senyor sabet" [SA7-40]), dedicado probablemente a Fernando de Guevara, Pedraza le anuncia poder hacer "juramento con osar" (v. 14) acerca de las virtudes de su amada; curiosamente, el poema que se copia a continuación es un Juramento escrito por Fernando de Guevara que constituye la toma formal de dicho acto (el texto ID2433 "Juras a nuestro senyor" [SA7-41]). Ello induce a pensar que quizá quisiese también provocar una reacción poética similar en don Diego con el Dezir. Garçía de Pedraza a Diego Furtado de Mendoza.

Por su parte, Pedraza, a pesar de la desdicha que ello le reporta, comparece ante su dedicatario como un iniciado acólito en el culto del dios profano (en ese sentido debe leerse la palabra "contenplaçión" en el verso 20, entendida como "aquel grado de Oracion sublime, à que llegan por favor de Dios, las almas mas adelantadas en su conocimiento y en su amór"; véase Diccionario de Autoridades, s. v. contemplación), de lo cual afirma tener pruebas escritas (nada menos que un lujoso documento validado por el dios de Amor con su firma: "vos puedo mostrar firmado / en rico paper escripto, / su nombre d'aquel bendito / dios d'Amor que da cuydado", vv. 1316). La mención de ese curioso documento, en el que Amor secundaría la demanda del pedrazano ante don Diego, junto con la solicitud de que medie en el envío de otro documento (el breve), han de vincularse, por cierto, con la penetración de aspectos procedentes del ámbito legal en la poesía cancioneril del cuatrocientos, en la que son frecuentes los trasvases de expresiones del lenguaje administrativo, notarial o judicial al ámbito amoroso, tal y como ocurre en este dezir ${ }^{27}$.

Dada la supuesta entidad eclesiástica de don Diego, y contando con la poderosa ayuda del propio dios de Amor (a quien sirve incondicionalmente), el poeta intentará lograr el favor de aquel para la consecución de su objetivo ("fazetme ser influydo / que leal soy namorado", vv. 27-28), que no es otro que el gozo amoroso, palpable en la utilización de un léxico con varios posibles niveles de lectura: es el caso de la demanda de canonización (v. 24) -que puede entenderse como una referencia a la consumación del amor- y, sobre todo, el de la solicitud de paso por un metafórico "puerto d'alegría" (vv. 7-8), que constituye una auténtica petición de acceso sexual al cuerpo femenino ${ }^{28}$. De especial relevancia literaria resulta esta última, pues su

El fenómeno se ha puesto en relación con las profesiones desempeñadas por los poetas cortesanos, muchos vinculados a estos entornos (burócratas, secretarios reales, nobleza de servicio, profesionales al servicio de la corte, etc.), lo que los haría estar familiarizados con los formulismos (Gómez Bravo, 2004: 87). No es este el único texto en que Pedraza se valdrá del procedimiento, pues también inició una de sus piezas con una conocida fórmula de notificación documental ("Sepan quantos esta carta / vieren", ID2413 "Sepan quantos esta carta" [SA7-22], vv. 1-2) y realizó el juramento de amor ante Fernando de Guevara (ID2432 "Fernando senyor sabet" [SA7-40] e ID2433 “Juras a nuestro senyor" [SA7-41]). Sobre el trasvase de fórmulas jurídicas a la literatura medieval véase el trabajo de Deyermond (2005b); para el ámbito cancioneril, con especial atención a los testamentos de amor, pueden consultarse Beltran (2001 y 2015: 53-68) y Chas Aguión (2006 y 2012b: 65-100).

28 Del mismo modo, en el seno de esta composición llega a afirmar que debe ser "guyado por el plazer" (v. 11), lo que remite de forma explícita a la satisfacción de sus apetencias sexuales. 
regusto serrano ("puerto" es, en su sentido recto, un paso entre montañas) parece ponerla en conexión con los episodios de la sierra del Libro de buen amor: según sostiene Vasvári, las serranas del arcipreste de Hita desarrollan el motivo del acto sexual entendido como un viaje o peregrinación por la topografía del cuerpo femenino; vocablos como "posada", "puerto" "camino", "vereda" o "paso" se encuentran en esta obra al servicio de este nivel interpretativo erótico (Vasvári, 1997, II:15661568). Además, como apunta Criado del Val, "pasar" y "paso" son dos términos equívocos usados en el Libro para denotar copulación (apud Montero, 2011: 21) ${ }^{29}$.

Ciertamente, no debería extrañar que Pedraza, como el arcipreste en su Libro, se valiese de un sintagma de reminiscencias serranas para aludir a la obtención del galardón amoroso, pues existen otras huellas en su obra que permiten ligarlo a aquella categoría poética (la más evidente es el ser autor de una serrana en colaboración con Rodrigo Manrique y Santillana), además de que su procedencia geográfica (Pedraza de la Sierra, localidad cercana a la serranía de Guadarrama) habla de un autor familiarizado con estos entornos ${ }^{30}$. Asimismo, el hecho de que este metafórico puerto sea el de la "alegría" ha de ponerse en relación con la recurrente presencia de este vocablo en su obra, siempre ocupando el vértice versal (como aquí sucede): "Amigo -dixe- alegría / el Senyor vos quiera dar" (ID2406 "Partiendo de madrugada" [SA7-13], vv. 55-56), "pues que con grant afecçión / me codicias, alegría" (ID2410 "Por ser de ti namorado" [SA7-18], vv. 7-8), "Traslado de alegría", "que, por el dios d'alegría, / vos juro, sin otra cossa" (ID2411 "Traslado de alegría" [SA7-20], vv. 1 y 17-18), "vos suplico qu'el tomar / sienta yo por alegría" (ID2423 "Pues demando aguinaldo" [SA7-27], vv. 7-8) ${ }^{31}$.

A este respecto, conviene apuntar que la alegría es un sentimiento de importante incidencia en la poética de Pedraza, un autor que se decanta en un mayor número de ocasiones por la expresión de una vivencia sentimental feliz o, siquiera, por un distanciamiento burlesco que minimiza la gravedad del ejercicio introspectivo. Así, y aunque la habitual queja por el rechazo de la dama es objeto de alguno de sus poemas, el escritor suele evitar esa enfermiza insistencia en el dolor de un amor desventurado en favor de otros desarrollos temáticos menos tristes, como el aquí planteado, dezir en el que es notoria la ironía y distensión con las que expresa su sicalíptica

Sobre el lenguaje ambiguo en los cancioneros véanse los clásicos trabajos de Whinnom (1981) y Macpherson (1985).

30 El componente serrano en la obra pedrazana se deja sentir especialmente en sus piezas relacionadas con Santillana y su hijo Diego Hurtado; ello resulta lógico si se tiene en cuenta que es esta una categoría literaria indefectiblemente asociada a la figura de Íñigo López de Mendoza durante el siglo XV, sin obviar que ambos tenían sus dominios en las proximidades de la sierra de Guadarrama (la rama principal de los Mendoza poseía la tierra de Buitrago, situada a escasos kilómetros de Pedraza de la Sierra). Y es que no solo la propia serrana compuesta con don Íñigo y Rodrigo Manrique (ID2424 "De Loçoya a Navafria" [SA7-28], etc.) remite a estas muestras poéticas y se ubica en este lugar, sino que una atmósfera serrana se respira también en la imitación pedrazana del Infierno de Íñigo López (ID2406 "Partiendo de madrugada" [SA7-13]) e incluso en su canción ID2420 "Alli tras daquella penya" (SA7-23), en la que el emplazamiento de un misterioso y afligido personaje "tras daquella penya" (v. 1) no deja de recordar a los versos del dezir a manera de cantiga que Pedro González de Mendoza (abuelo de Santillana) escribió a una serrana en los albores del fenómeno cancioneril (ID1388 "Menga dame el tu acorro"): "Menga, tras aquella peña / allí nos vamos casar; / do el agua se despeña, / allí fagamos yantar" (vv. 25-28) -citado por Dutton y Roncero (2004).

31 A estos ejemplos todavía podrían sumarse los versos "cada qual d'ellos non quito / ser en muy poca alegría" (ID2406 "Partiendo de madrugada" [SA7-13], vv. 35-36), si bien en este caso la voz es utilizada en un sentido negativo. Al igual que las del texto objeto de estudio, las citas de otros poemas del autor se toman de la edición del Cancionero de Palacio de Álvarez Pellitero (1993). 
petición, demanda que, indudablemente, se encuentra al servicio de la carcajada del público cortesano.

Pero no solo el poema apunta hacia un nivel interpretativo erótico, sino que también el curioso dibujo que figura en el margen inferior del folio $15 \mathrm{r}$ refuerza esta idea pues, como se puede apreciar, en él se representa una escena en la que una dama vestida azota con un látigo a un hombre desnudo y maniatado; de la boca de ella, cual si de una moderna viñeta de cómic se tratase, salen las elocuentes palabras "por el puerto d'alegría non passarás", a las que el varón responde con el octosílabo "assaz penas e cuydado" 32 . Tanto este dibujo como las capitales que adornan el folio parecen debidas a una misma mano (la tinta es uniforme), y lo cierto es que la imagen se sustenta en el dezir, pues ese breve diálogo remite a su contenido: como se ha visto, en él Pedraza planteaba su demanda casi en los mismos términos en que se expresa la mujer de la escena ("que me dexen ya passar / por el puerto d'alegría", vv. 7-8); igualmente, el poeta confesaba padecer por amor "asaç penas et cuydado" (v. 4), palabras que proporciona la respuesta del caballero azotado.
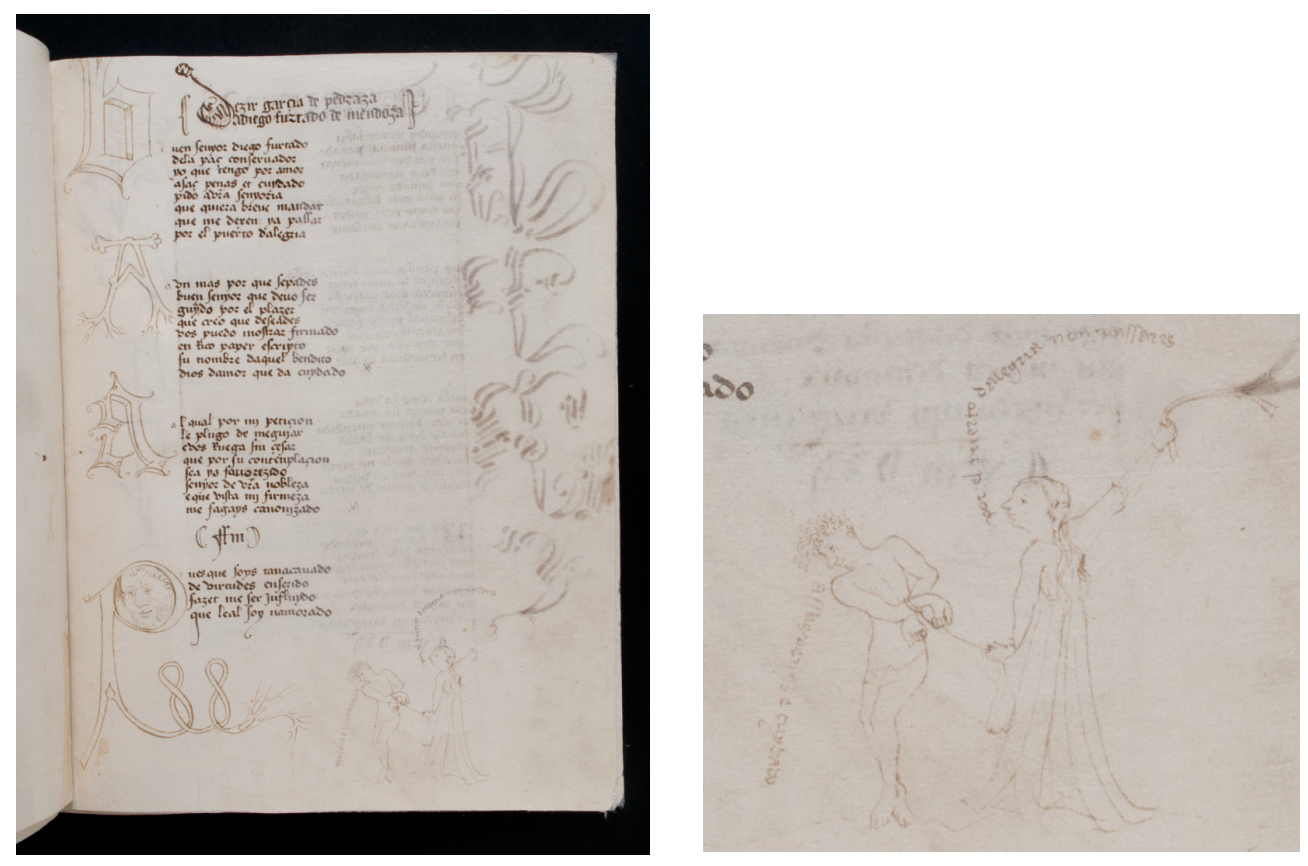

Todo ello abre otras posibilidades hermenéuticas del poema, pues esta escena de tintes masoquistas clarificaría el motivo por el cual la amada es cruel y elusiva con su pretendiente: no es que rechace su cortejo, sino solo sus intenciones sexuales (Montero, 2011: 21) 33 .

32 Las imágenes empleadas han sido tomadas de la reproducción digital del códice disponible en el Repositorio Documental de la Universidad de Salamanca < http://hdl.handle.net/10366/81629> [visitado el 20 de abril de 2017].

33 El Cancionero de Palacio constituye "a work which can only be fully appreciated through the dual processes of reading and looking” (Gerli, 2001: 9). Para la decoración de SA7 véase Tato (2003: 506-509). 
En otro orden de cosas, todavía cabría preguntarse si la parca frase en boca del hombre de la viñeta, coincidente con el cuarto verso ("asaç penas et cuydado"), es casual o premeditada, pues ya Vendrell en su valiosa edición del Cancionero de $\mathrm{Pa}$ lacio calificaba estas palabras de divisa del pedrazano (1945: 60). Lo cierto es que la brevedad y concisión de la sentencia, unida a la frecuente aparición del vocablo "pena/s" con sentido dilógico en motes e invenciones (Rico, 1990: 189-230), da pie a conjeturar que quizá "asaç penas et cuydado" hubiese funcionado como mote de García de Pedraza; y es que, pese a haber alcanzado un desarrollo mucho mayor en la segunda mitad del siglo XV (Casas Rigall, 1995: 125), esta categoría literaria no es ajena a SA7, en el que figuran incluso dos rúbricas que anuncian motes: uno de Contreras y otro de Juan de Torres (Tato, 2010b). Se trata de una modalidad poética basada plenamente en la brevitas, ocho sílabas en las que se condensaba un pensamiento o estado de ánimo habitual o pasajero y que normalmente portaban como lema caballeros y damas en los eventos de la corte (Le Gentil, 1949-1952, I: 214; Macpherson, 2004: 10-11). Los motes podían tener vida independiente, grabados en la ropa o en las armas, o servir de cabeza a una glosa en la que se explicaba el pensamiento en ellos condensado, un género que tuvo especial representación en el Cancionero general. A pesar de que es poco lo que se sabe sobre estas muestras poéticas en la primera mitad del siglo XV, no solo existieron en esa época (como prueba SA7, que atesora los motes probablemente más antiguos conservados), sino que parecen haber gozado de una mayor importancia de la que hasta ahora se les ha supuesto (Tato, 2012: 309): quizá "asaç penas et cuydado" pueda constituir una nueva muestra del género ${ }^{34}$.

En fin, el análisis detenido de esta pieza ha permitido, por un lado, arrojar luz sobre la biografía de su autor y destinatario, a quienes habría que identificar, respectivamente, con García de Herrera y Enríquez, tercer señor de Pedraza (nac. $c$. 1415 - $\uparrow 1483$ ) y Diego Hurtado de Mendoza y Figueroa, hijo primogénito del marqués de Santillana (nac. c. 1415-1417 - †1479), dos jóvenes poetas del Cancionero de Palacio unidos por la vinculación que ambos mantuvieron con Íñigo López de Mendoza. Por otro lado, el poema interesa en cuanto vivo testimonio del componente lúdico-cortesano que caracteriza a este tipo de poesía, en la que las relaciones literarias entre autores no se limitan a la cita de versos ajenos, sino que conocen otras manifestaciones, como lo es la inclusión de un autor cancioneril como personaje ficcionalizado en una pieza. Por último, el contenido de la misma, junto con el dibujo que la acompaña en el manuscrito, aquilata las posibilidades interpretativas que despliega el lenguaje cancioneril.

34 Sobre el mote pueden consultarse las páginas que a él dedica Whinnom (1981: 57-62) o el estudio de Macpherson (2004); son también útiles Le Gentil (1949-1952, I: 214-215), Casas Rigall (1995: 122-126) o Rodado Ruiz (2000: 173-174). Sobre este género en la primera mitad del siglo XV se ocupó Tato en dos comunicaciones todavía inéditas (2010b y 2016); para el de Contreras en SA7 véase Tato (2013) y el de Juan de Torres en Mosquera Novoa (2016: 95-97). 


\section{Texto completo}

Dezir. Garçía de Pedraza a Diego Furtado de Mendoza

Buen senyor Diego Furtado, de la paç conservador, yo, que tengo por amor asaç penas et cuydado, pido a vuestra senyoría que quiera breve mandar: que me dexen ya passar por el puerto d'alegría.

Aún más, por que sepades, buen senyor, que devo ser guyado por el plazer que creo que deseades, vos puedo mostrar firmado en rico paper escripto su nombre d'aquel bendito dios d'Amor que da cuydado.

Al qual, por mi petición, le plugo de me guiar, e vos ruega sin çesar que, por su contenplaçión, sea yo favorezido, senyor, de vuestra nobleza, e, que vista mi firmeza, me fagáys canonizado.

\section{Fin}

Pues que soys tan acavado, de virtudes enserido, fazetme ser influydo, que leal soy namorado.

\section{Obras citadas}

Alemany y Bolufer, José: Diccionario de la lengua española, Barcelona, Ramón Sopena Editor, 1917.

Álvarez Pellitero, Ana María (ed.): Cancionero de Palacio, Salamanca, Junta de Castilla y León, 1993.

Beltran, Vicenç: "Copistas y cancioneros", en Edición y anotación de textos. Actas del I Congreso de Jóvenes Filólogos, I, Carmen Parrilla et alii (ed.), La Coruña, Universidade da Coruña, 1998, pp. 17-40. 
Beltran, Vicenç: "El Testamento de Alfonso Enríquez", en Convergences médiévales. Épopée, lyrique, roman: Mélanges offerts à Madeleine Tyssens, Nadine Henrard et alii (ed.), Bruxelles, De Boeck University, 2001, pp. 63-76.

Beltran, Vicenç: "Anonymity and opaque attributions in late-medieval poetry compilations", Scriptorium, LVIII (2004), pp. 26-47.

Beltran, Vicenç: Pruébase por escritura. Poesía y poetas del cuatrocientos, Alcalá de Henares, Universidad de Alcalá, 2015.

Campos Souto, María Begoña: "El juego cortesano dentro del juego poético en el Cancionero de Palacio (SA7): sobre el posible contexto de una serrana compuesta en colaboración", Cancionero General, VI (2008), pp. 9-32.

Campos Souto, María Begoña: Poetas menores de apellido Manrique. Edición y estudio, Tesis doctoral inédita, Universidade da Coruña, 2012.

Canellas López, Ángel (ed.): Anales de la Corona de Aragón, Jerónimo Zurita, Zaragoza, Institución 'Fernando el Católico', 1977-1990.

Casas Rigall, Juan: Agudeza y retórica en la poesía amorosa de cancionero, Santiago de Compostela, Universidade de Santiago de Compostela, 1995.

Chas Aguión, Antonio: "Los testamentos en la poesía de cancionero", Revista de poética medieval, 16 (2006), pp. 53-78.

Chas Aguión, Antonio: "Los diálogos interestróficos en el Cancionero de Palacio (SA7)", Romance Quarterly, 59:4 (2012a), pp. 195-210.

Chas Aguión, Antonio: Categorías poéticas minoritarias en el cancionero castellano del siglo XV, Alessandria, Edizioni dell'Orso, 2012b.

Crosas, Francisco: "Notas sobre el uso de textos bíblicos 'a lo profano' en la poesía tardomedieval”, en La Biblia en el arte y en la literatura. V Simposio Bíblico español, I, Vicente Balaguer et alii (ed.), Valencia-Pamplona, Fundación Bíblica Española, 1999, pp. 177188.

Crosas, Francisco: "La religio amoris en la literatura medieval", en 'La fermosa cobertura': lecciones de literatura medieval, Francisco Crosas (ed.), Pamplona, EUNSA, 2000, pp. 101-128.

Deyermond, Alan: "Las relaciones literarias en el siglo XV", en Actas del X Congrès Internacional de l'Associació Hispànica de Literatura Medieval, I, Rafael Alemany et alii (ed.), Alicante, Institut Interuniversitari de Filologia Valenciana, 2005a, pp. 73-92.

Deyermond, Alan: “'Sí, ministro': Las prácticas administrativas en la literatura medieval española”, en Actas del IX Congreso Internacional de la Asociación Hispánica de Literatura Medieval (A Coruña, 18-22 de septiembre de 2001), I, Carmen Parrilla y Mercedes Pampín (ed.), Noia, Toxosoutos, 2005b, pp. 127-155.

Domínguez, Ramón Joaquín: Diccionario nacional ó Gran diccionario clásico de la lengua española, Madrid, Establecimiento léxico-tipográfico de R. J. Domínguez, 1846-1847.

Dutton, Brian: "Spanish Fifteenth-Century Cancioneros: A General Survey to 1465", Kentucky Romance Quarterly, XXVI (1979), pp. 445-460.

Dutton, Brian: El cancionero del siglo XV, c. 1360-1520, Salamanca, Biblioteca Española del Siglo XV-Universidad de Salamanca, 1990-1991.

Dutton, Brian y Victoriano Roncero López (ed.): La poesía cancioneril del siglo XV. Antología y estudio, Madrid, Iberoamericana, 2004.

Garcia, Michel: "La noción de género en el corpus cancioneril: el caso de la serrana", en Los cancioneros de Lucrezia (Atti del convegno internazionale sulle raccolte poetiche iberiche dei secoli XV-XVII), Andrea Baldissera y Giuseppe Mazzocchi (ed.), Padova, Unipress, 2005, pp. 25-41. 
Garribba, Aviva (ed.): De rúbricas ibéricas, Roma, Aracne, 2008.

Gerli, Michael: 'La 'religión del amor' y el antifeminismo en las letras castellanas del siglo XV”, Hispanic Review, 49/1 (1981), pp. 65-86.

Gerli, Michael: "On the Edge: Envisioning the Libro de buen amor in the Cancionero de Palacio", eHumanista: Journal of Iberian Studies, 1 (2001), pp. 1-11.

Gernert, Folke: Parodia y 'contrafacta' en la literatura románica medieval y renacentista: historia, teoría y textos, San Millán de la Cogolla, Cilengua, 2009.

Giuliani, Luigi: “Tapia y Juan de Tapia: un caso de homonimia en los cancioneros", Anuario brasileño de estudios hispánicos, I (1991), pp. 49-62.

Gómez Bravo, Ana María: Repertorio métrico de la poesía cancioneril del siglo XV, Alcalá de Henares, Universidad de Alcalá, 1998.

Gómez Bravo, Ana María: "Memorias y archivos. Modelos de producción textual y antologías poéticas del siglo XV”, Cancionero General, 2 (2004), pp. 53-87.

Gómez Moreno, Ángel y Maximiliam P.A.M. Kerkhof (ed.): Obras completas, Íñigo López de Mendoza, Marqués de Santillana, Barcelona, Planeta, 1988.

Le Gentil, Pierre: La poésie lyrique espagnole et portugaise a la fin du Moyen Âge, Rennes, Plihon, 1949-1952.

Lida de Malkiel, María Rosa: "La hipérbole sagrada en la poesía castellana del siglo XV", en Estudios sobre la literatura española del Siglo XV, Madrid, J. Porrúa Turanzas, 1977, pp. 291-309.

López Drusetta, Laura: “Una temprana imitación del Infierno de Santillana en un poema de García de Pedraza recogido en el Cancionero de Palacio", en Parodia y debate metaliterarios en la Edad Media, Mercedes Brea et alii (ed.), Alessandria, Edizioni dell'Orso, 2013, pp. 429-442.

López Drusetta, Laura: “¿Fue el poeta cancioneril Diego Hurtado de Mendoza almirante de Castilla?”, Bulletin of Hispanic Studies, 91.8 (2014), pp. 867-879.

López Drusetta, Laura: "En torno a la identificación de García de Pedraza, poeta de cancionero", en Estudios de literatura medieval en la Península Ibérica, Carlos Alvar (ed.), San Millán de la Cogolla, Cilengua, 2015, pp. 847-860.

López Drusetta, Laura: "El entorno poético de García de Pedraza en SA7”, en De lagrymas faziendo tinta, Virginie Dumanoir (ed.), Madrid, Casa de Velázquez, 2017a

López Drusetta, Laura: “Algunas notas sobre la obra poética de García de Pedraza”, Pavia, Editorial Ibis, en prensa.

López Drusetta, Laura: Poetas del Cancionero de Palacio (SA7): Diego Hurtado de Mendo $\neg-$ za, García de Pedraza y mosén Moncayo. Edición y estudio de su poesía, Tesis doctoral, Universidade da Coruña, 2017b.

Macpherson, Ian: "Secret Language in the Cancioneros: Some Courtly Codes", Bulletin of Hispanic Studies, 62/1 (1985), pp. 51-63.

Macpherson, Ian: Motes y glosas in the Cancionero General, London, Department of Hispanic Studies-Queen Mary, 2004.

Montero, Ana Isabel: "From Margins to the Centre: Libidinous Imagery in MS. 2653 of the Cancionero de Palacio", Bulletin of Hispanic Studies, 88/1 (2011), pp. 1-23.

Moreno, Manuel: "La autoría como problema en la edición de la obra poética de Nicolás Núñez, poeta del Cancionero General (Valencia, 1511)", en Edición y anotación de textos. Actas del I Congreso de Jóvenes Filólogos, II, Carmen Parrilla et alii (ed.), La Coruña, Universidade da Coruña, 1998, pp. 463-478.

Mosquera Novoa, Lucía (ed.): La poesía de Juan de Torres, Alessandria, Edizioni dell'Orso, 2016. 
Oreja Andrés, Sila: “Ceremonia, fiesta y poder durante los reinados de Juan II y Enrique IV de Castilla: el arte textil como síntoma de prestigio, a la luz de las Crónicas", Anales de Historia del Arte, 23 (2013), pp. 321-333.

Palomo Fernández, María Gema y José Luis Senra Gabriel y Galán: "La ciudad y la fiesta en la historiografía castellana de la Edad Media: escenografía lúdico-festiva", Hispania: Revista Española de Historia, 54/186 (1994), pp. 5-36.

Pérez Priego, Miguel Ángel (ed.): Poesías, Marqués de Santillana, Madrid, Cátedra, 1999.

Pidal, Pedro José et alii (ed.): El cancionero de Juan Alfonso de Baena, Madrid, Rivadeneyra, 1851.

Real Academia Española, Diccionario de Autoridades, Madrid, Real Academia Española, 1726-1739.

Repositorio Documental de la Universidad de Salamanca <http://gredos.usal.es/jspui/>

Rico, Francisco: Texto y contextos. Estudios sobre la poesía española del siglo XV, Barcelona, Crítica, 1990.

Ríos, José Amador de los (ed.): Obras de don Ínigo López de Mendoza, Marqués de Santillana, ahora por vez primera compiladas de los códices originales e ilustradas con la vida del autor, notas y comentarios, Madrid, Imprenta de la Calle de S. Vicente, José Rodríguez, 1852.

Ríos, José Amador de los: Historia crítica de la literatura española, Madrid, Imprenta a cargo de José Fernández Cancela, 1861-1865.

Rodado Ruiz, Ana María: 'Tristura conmigo va': fundamentos de amor cortés, Cuenca, Ediciones de la Universidad de Castilla-La Mancha, 2000.

Saguar García, Amaranta: Intertextualidades bíblicas en Celestina: devotio moderna y hu-manismo cristiano, Vigo, Editorial Academia del Hispanismo, 2015.

Salazar y Acha, Jaime: Manual de genealogía española, Madrid, Hidalguía, 2006.

Tato, Cleofé: "Poetas cancioneriles de apellido 'Montoro", Revista de literatura medieval, 10 (1998), pp. 169-181.

Tato, Cleofé: "Breve noticia sobre la historia del Cancionero de Palacio", en Estudos dedicados a Ricardo Carvalho Calero, II, José Luis Rodríguez (ed.), Santiago de Compostela, Parlamento de Galicia-Universidade de Santiago de Compostela, 2000, pp. 725-731.

Tato, Cleofé: "El Cancionero de Palacio (SA7), ms. 2653 de la Biblioteca Universitaria de Salamanca (I)", en Cancioneros en Baena: Actas del II Congreso Internacional Cancionero de Baena, I, Jesús L. Serrano Reyes (ed.), Baena, Ayuntamiento de Baena, 2003, pp. 495-523.

Tato, Cleofé: "Huellas de un cancionero individual en el Cancionero de Palacio (SA7)", en Los cancioneros españoles: materiales y métodos, Manuel Moreno y Dorothy S. Severin (ed.), London, Department of Hispanic Studies, Queen Mary and Westfield College, 2005, pp. 61-90.

Tato, Cleofé: “¿Una mujer con voz en el Cancionero de Palacio (SA7)?”, en Convivio: estudios sobre la poesía de cancionero, Vicenç Beltran y Juan Paredes (ed.), Granada, Universidad de Granada, 2006, pp.787-811.

Tato, Cleofé: "Un acercamiento al problema de las atribuciones en el Cancionero de Palacio", en Convivio: cancioneros peninsulares, Vicenç Beltran y Juan Paredes (ed.), Granada, Universidad de Granada, 2010a, pp. 215-234.

Tato, Cleofé: "Los motes de la primera mitad del siglo XV", comunicación leída en el VI Congreso Internacional de Lyra Minima, celebrado en San Millán de la Cogolla del 20 al 23 de octubre de 2010 b.

Tato, Cleofé: "Prolegómenos a la edición del Cancionero de Palacio (SA7)", en O texto 
medieval: da edición á interpretación, Pilar Lorenzo Gradín y Simone Marcenaro (ed.), Santiago de Compostela, Universidade de Santiago de Compostela, 2012, pp. 299-318.

Tato, Cleofé: "Se vende y se compra: la almoneda poética del mote de Contreras", en Parodia y debate metaliterarios en la Edad Media, Mercedes Brea et alii (ed.), Alessandria, Edizioni dell'Orso, 2013, pp. 379-403.

Tato, Cleofé: "La métrica del Cancionero de Palacio", en Historia de la métrica medieval castellana, Fernando Gómez Redondo (coord.), San Millán de la Cogolla, Cilengua, 2016.

Tato, Cleofé: "De nuevo sobre los motes en la primera mitad del siglo XV", comunicación leída en el V Congreso Internacional Poesía, poéticas y cultura literaria de la Asociación Convivio para el estudio de los cancioneros y de la poesía de cancionero, celebrado en Verona del 18 al 20 de febrero de 2016.

Tillier, Jane Yvonne: "Passion Poetry in the Cancioneros", Bulletin of Hispanic Studies, LXII (1985), pp. 65-78.

Vasvári, Louise O.: "Peregrinaciones por topografías pornográficas en el Libro de buen amor", en Actas del VI congreso internacional de la Asociación Hispánica de Literatura Medieval, II, José Manuel Lucía Megías (ed.), Alcalá de Henares, Universidad de Alcalá, 1997, pp. 1563-1572.

Vendrell, Francisca (ed.): El Cancionero de Palacio (manuscrito $n^{\circ}$ 594), Madrid, C.S.I.C., 1945.

Whinnom, Keith: La poesía amatoria de la época de los Reyes Católicos, Durham, University of Durham, 1981. 